\title{
Dwellers' Habit of Opening Windows in Detached Houses in Cold and Hot-Humid Climate of Japan
}

\author{
Motoya Hayashi $^{1}$, Yoshinori Honma ${ }^{2}$, Masanori Sugawara ${ }^{3}$ \\ ${ }^{1}$ Department of Life Style and Space Design, Miyagigakuin Women's University, Sendai, Japan \\ ${ }^{2}$ Iwate prefectural University, Takizawa, Japan \\ ${ }^{3}$ Miyagi University of Education, Sendai, Japan \\ Email: mhns01234@aol.com
}

Received 29 April 2014; revised 22 May 2014; accepted 5 June 2014

Copyright (C) 2014 by authors and Scientific Research Publishing Inc.

This work is licensed under the Creative Commons Attribution International License (CC BY).

http://creativecommons.org/licenses/by/4.0/

(c) (i) Open Access

\begin{abstract}
The design of openings is important for sustainable living in the cooling climate. Dweller's habit of opening windows was investigated in nine Japanese detached houses using a window monitor originated by the author. The monitor measures the open width of sliding window and record daily and annual changes. The performance of a house and the living style of its dweller were investigated using questions to the dwellers. The investigation gave the following results. Windows were closed not only at night but also in the day time even in mild seasons in most houses. The average open widths were very small in mild and hot seasons in most houses. The daily and annual changes of open widths are very various. The open widths of windows are influenced by many factors; the type of a room, the number of a floor, the living schedule of dwellers, thermal performances of a house and the equipment for heating or cooling and the weather conditions. Therefore these factors have to be reconsidered to design effective windows.
\end{abstract}

\section{Keywords}

Energy Saving, Indoor Air Quality, Window, Dweller's Behavior, Long Term Field Measurement

\section{Introduction}

In Japan, it is cold in winter and hot and humid in summer. The heating load of new houses has decreased with the insulation and the airtight based on the recent building guidelines. But the energy consumption for cooling has been rapidly increasing with the diffusion of air conditioners to Japanese houses. In the traditional Japanese 
houses, the wind passes through the wide sliding windows cools indoor space and dweller's bodies. At night the hot air is exhausted through upside openings and the cool air is supplied through these windows. These sliding windows are still used in the most rooms of recent common houses. The dwellers open them not only when they feel hot or humid but also in every morning and when they clean rooms even in winter. They have operated the open widths of the sliding windows to make indoor space comfortable. However, these opening habits have been decreasing because general living styles and surrounding conditions have changed especially in the urban areas. The diffusion of air conditioners is another reason. In these changes, the traditional natural cooling strategies are now reevaluated for reducing cooling energy consumption and carbon dioxide emission from houses.

In common houses, these sliding windows are in-stalled and they can be opened by the dwellers. However, the windows are not opened effectively in many cases, even in mild seasons, in order to prevent out-side noise, air pollution, burglaries or mosquitoes and other insects from coming in and to secure privacy. Therefore, the guidelines for designing effective openings in the modern houses are needed for indoor comfort and saving energy. Before making these guidelines, the daily habits of opening windows were surveyed to know when and how often windows are opened in common houses.

The investigations on the relationship between indoor comfort and window operation have been carried out [1] [2]. The behavior related to the indoor climate and the cooling energy was investigated [3]-[5]. Basically the dwellers open windows when they feel hot and close them when they feel cold. The other factors had been recognized too. The authors composed a simulation program named "Fresh" with the consideration of the basic dweller's behavior [6] [7].

In this study, the dweller's opening habits were investigated using a new measuring system in the case of sliding windows in Japanese detached houses.

\section{Methods}

In order to know the state of windows in houses, a monitor instrument to measure the open width at a sliding window was devised. The instrument consists of pulleys, a piece of string, a spring, a potential meter and a recorder as shown in Figure 1 and Figure 2. When a dweller opens a sliding window, the sucking disk on the glass pulls the string and the pulley and the potential meter rotates. When dweller closes the sliding window, the thread is rewound by the spring. The recorder records the resistance of the potential meter. In this investigation, resistance was recorded every 10 minutes. The open width is calculated using the recorded resistance. Not only the open width but also the temperature and the humidity both in the room and outside were measured successively for almost a year. The measurements were carried out in nine detached houses from the temperate zone to the sub frigid zone in Japan from 2003 to 2004. The living habits and the building types were investigated using a questionnaire form.

Table 1 shows the investigated houses. These houses are two storied detached houses. The structures of these houses are a wooden beam and pillar, a steal frame, or a wooden panel. The most common structure of Japanese houses is wooden beam and pillar. It is similar to the traditional structure which has wide openings and air flow routes in the wall, the crawl space, the beam space and the attic space. The houses with a steal frame and with a wooden panel structure are prefabricated houses made in large factories of a housing company. The airtight and insulation levels depend on the year of construction and the area, be-cause these houses were designed according to the construction standards at that time in Japan.

Figure 3 shows the locations of houses. Hokkaido is in the sub frigid climate zone. The other areas are in the temperate zone. The number of a family is from 2 to 4 . In the house "Hokkaido 1", fuel heaters with forced flow

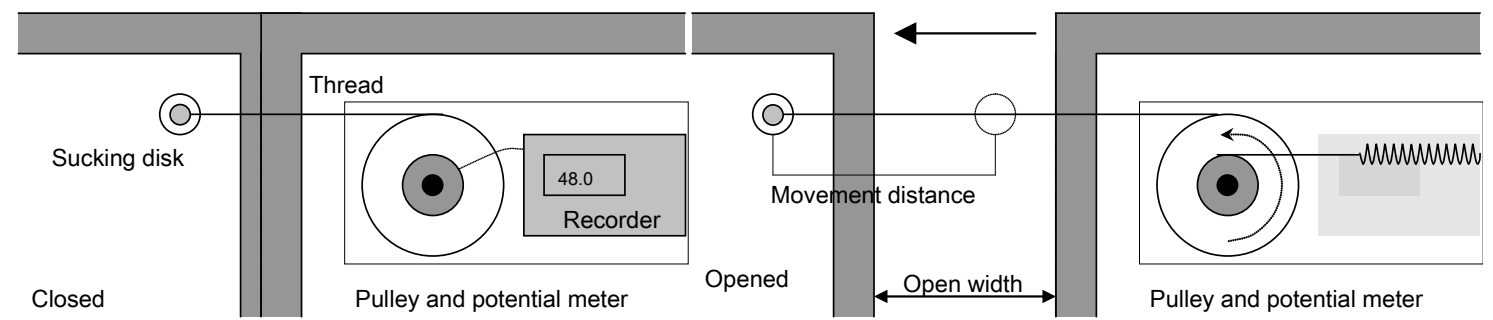

Figure 1. Open width monitor at a sliding window. 


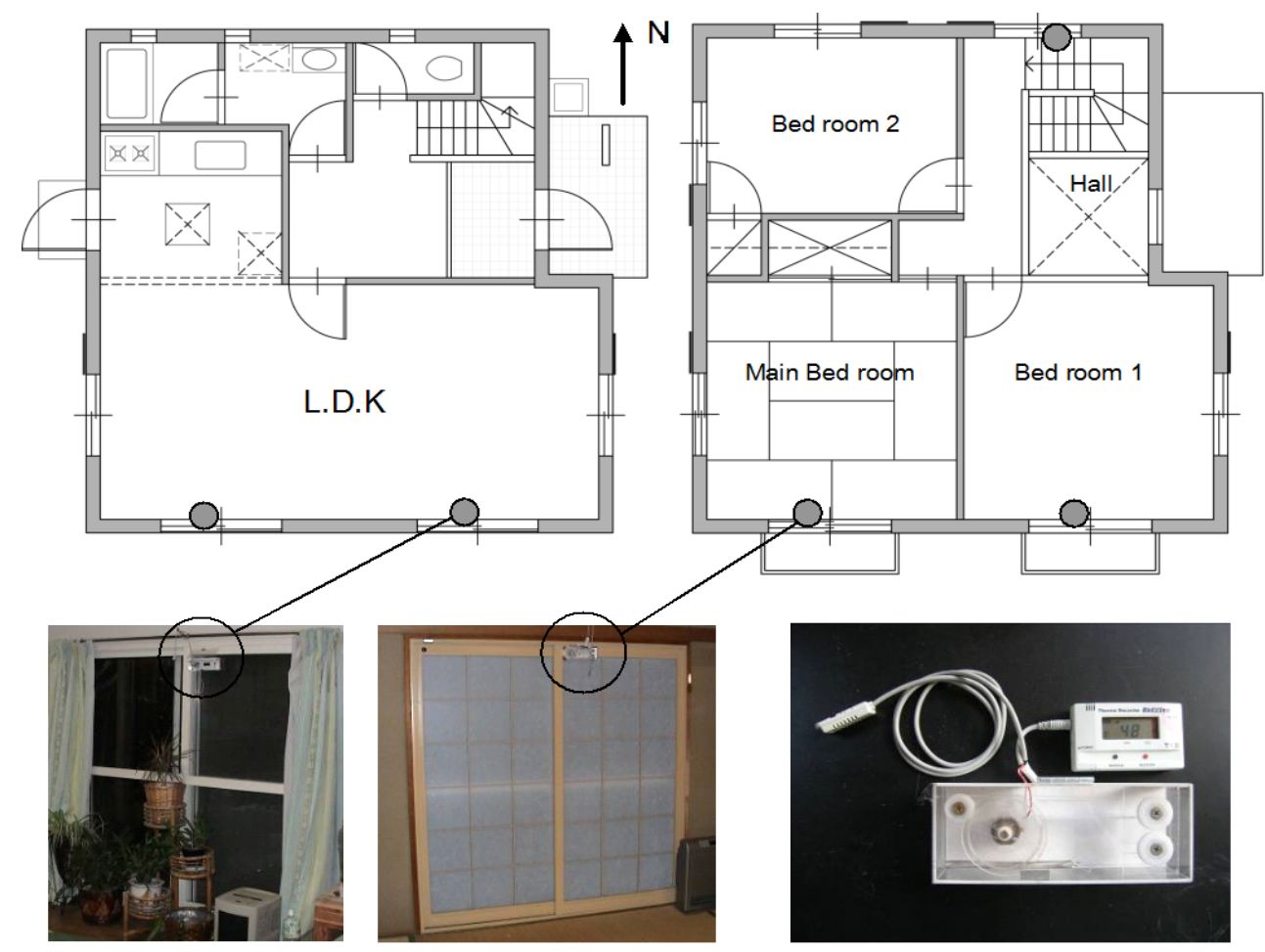

Open width monitor

Figure 2. Open width monitors in an investigated house (Miyagi 1).
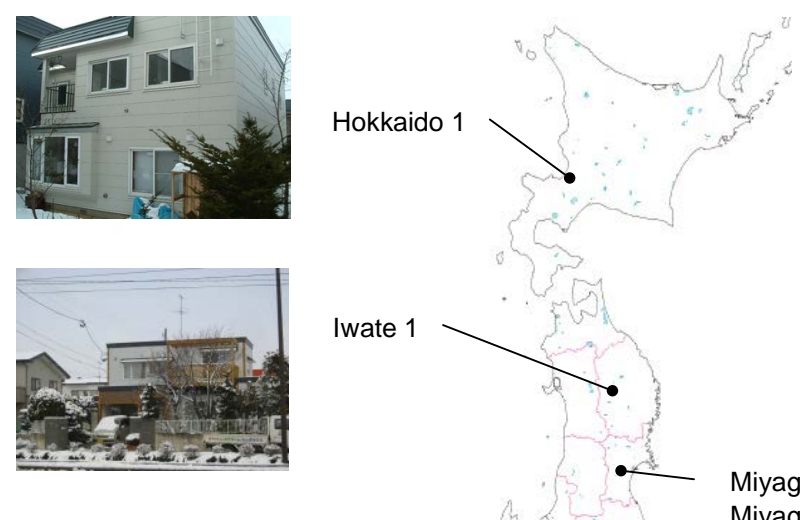

Miyagi 1

Miyagi 2
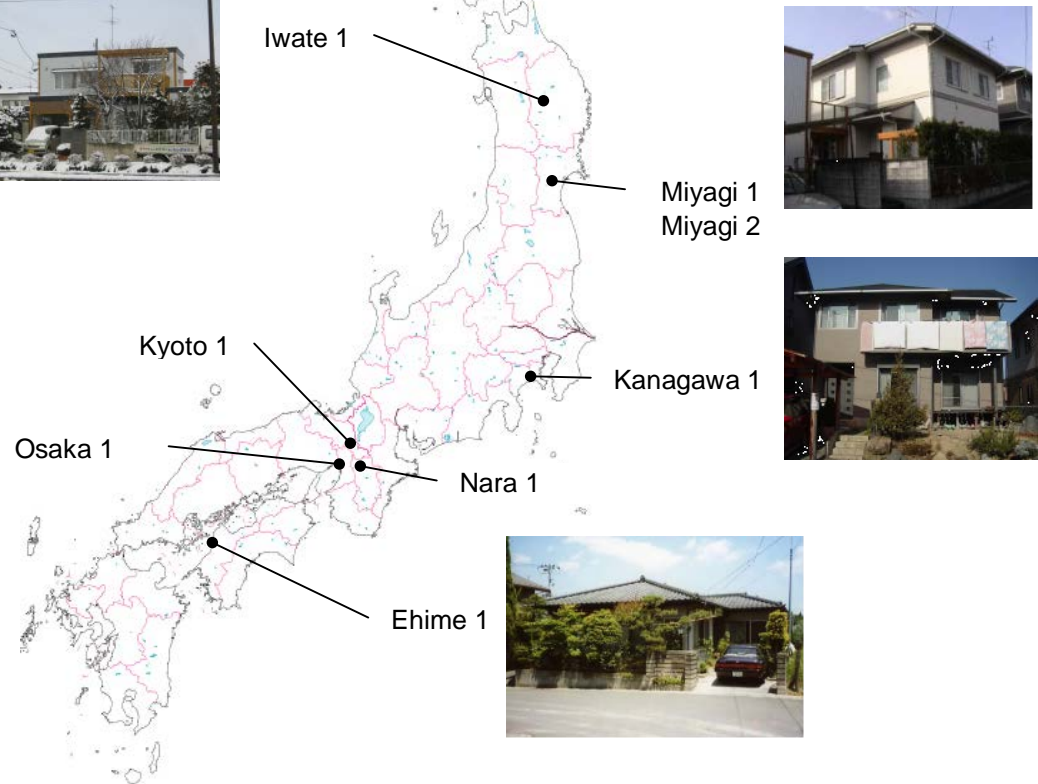

Figure 3. Distribution of investigated houses. 
Table 1. Investigated houses.

\begin{tabular}{ccccc}
\hline & Construction & Structure & Plan/floor $\left(\mathrm{m}^{2}\right)$ & Heating/Cooling \\
\hline Hokkaido 1 & 1988 & Wooden beam and pillar & $4 \mathrm{LDK} / 164$ & Fuel heater/no cooling \\
Iwate 1 & 2003 & Wooden beam and pillar & $4 \mathrm{LDK} / 133$ & Electric heater with brick storage/heat pump \\
Miyagi 1 & 1986 & Wooden panel & 3LDK/100 & Fuel heater/heat pump \\
Miyagi 2 & 1979 & Steal frame & 4LDK/105 & Fuel heater without exhaust system/heat pump \\
Kanagawa 1 & 1986 & Steal frame & 4LDK/108 & Fuel heater without exhaust system/heat pump \\
Kyoto 1 & 1999 & Steal frame & 3LDK/132 & Heat pump/heat pump \\
Nara 1 & 2001 & Steal frame & 2LDK/115 & Fuel heater/heat pump \\
Osaka 1 & 1991 & Steal frame & 5LDK/196 & Gas heater without exhaust system/heat pump \\
Ehime 1 & 1995 & Wooden beam and pillar & 3LDK/138 & Fuel heater without exhaust system/heat pump \\
\hline
\end{tabular}

are used and no cooling system is used. In the house "Iwate1", the heaters with brick storages using electric power at night and air conditioners with a heat pump are used. In the house "Miyagi 1", a heating system with fan convectors and a boiler is used and an air conditioner is used for cooling in L.D.K., a space consist of a living space, a dining space and a kitchen. In this space, fans are used for body-cooling too. In the study, this kind of fan is used in the house located in the southern area from Miyagi. In "Miyagi 2" and "Kanagawa 1", fuel heaters without an exhaust system are used and air conditioners are used. In "Kyoto 1", air conditioners with heat pumps are used for heating and cooling. In "Nara 1", a heating system with radiators and a boiler is used and air conditioners are used for cooling. In "Osaka 1", gas heaters without an exhaust system are used in the living room and air conditioners are used for heating and cooling. In "Ehime 1", fuel heaters without an exhaust system are used in the living room and an electric heater is used in the main bedroom. Air conditioners are used for heating and cooling. These houses are located in the suburb of the city and the surrounding condition is not worse than the general condition in Japan.

\section{Results}

Figure 4 shows the changes of open widths and the temperatures in the house Miyagi 1 in August. The open widths of the two southern sliding windows of L.D.K. changed with the temperatures. Basically, dwellers open the windows fully in the morning and close them at night when they sleep. When they went out after noon in the daytime on August, they closed them and the room temperature became higher. When they came back, they opened the windows fully and the room temperature became close to the ambient temperature. This daily cycle was recognized from June to September.

The change of the open width in the main bedroom on the second floor is not the same as that in L.D.K. The dwellers open windows fully in the morning and regulate open width at night when they sleep considering indoor comfort and outdoor condition. In the case of rooms on the second floor, they can sleep safely even when the windows are open. Therefore they can control open width to get a better sleeping.

Figure 5 shows the annual change of the open widths and the room temperatures. The total open width of two windows in L. D. K. changes with the temperature. Dwellers open windows usually before October and after the middle of June. In the case of the main bed room, they open windows usually before November and after March. The open width of Hall, which is measured at the north window on the second floor, shows different change from the above cases. Dwellers did not operate the windows every day. They open the window before October and after the end of July. Dwellers know that when the window is open, much of the inside hot air is exhausted and the effect of wind pass becomes higher.

These characteristics of open width where also recognized in other houses. These results shows that the change of open width depends on the indoor physical environment, the indoor temperatures etc. basically. The change depends on the behaviors of dwellers too. The behavior depends not only on the living schedule of dweller but also on the knowledge of the effect of wind pass and ventilation upon indoor comfort. 

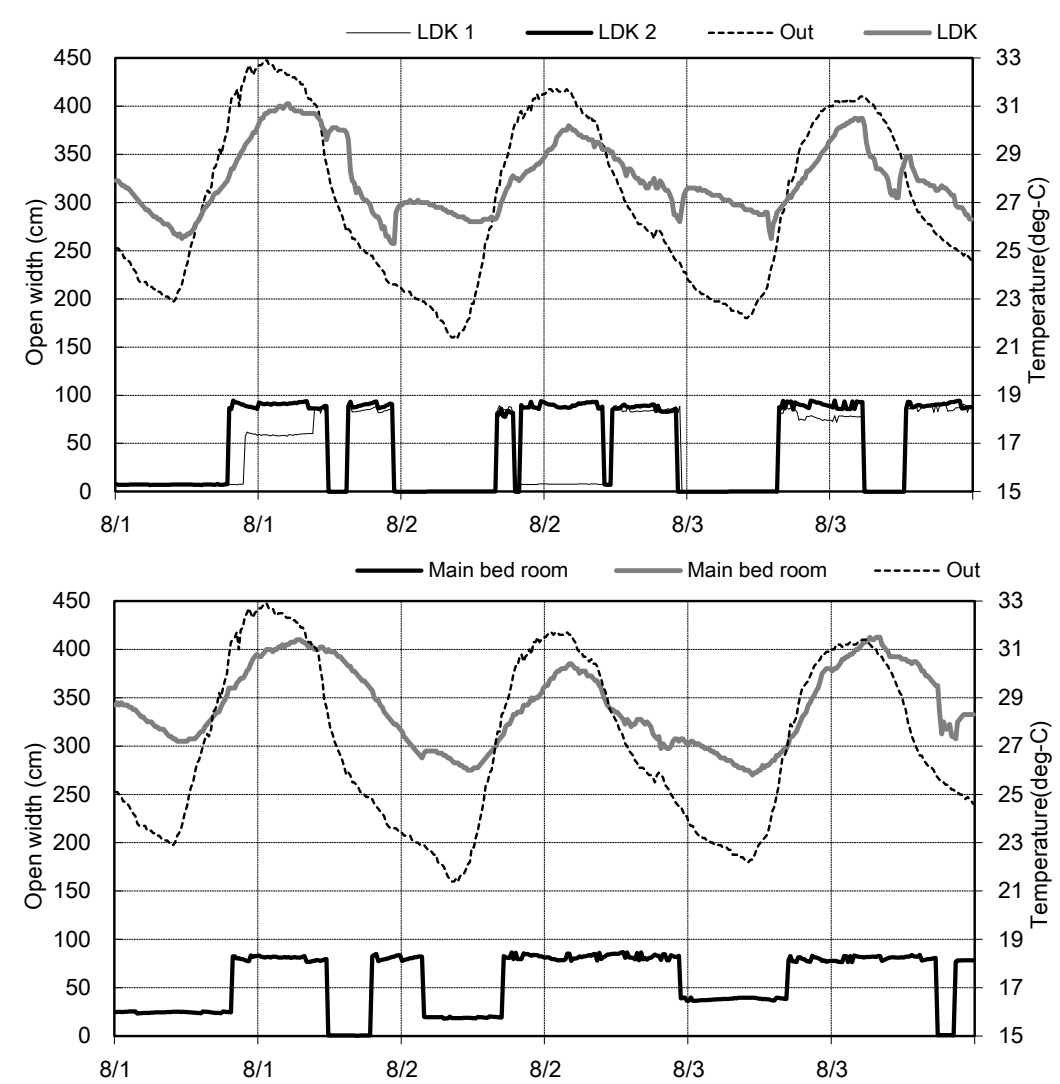

Figure 4. Change of the open width and the temperature in a house: Miyagi 1.
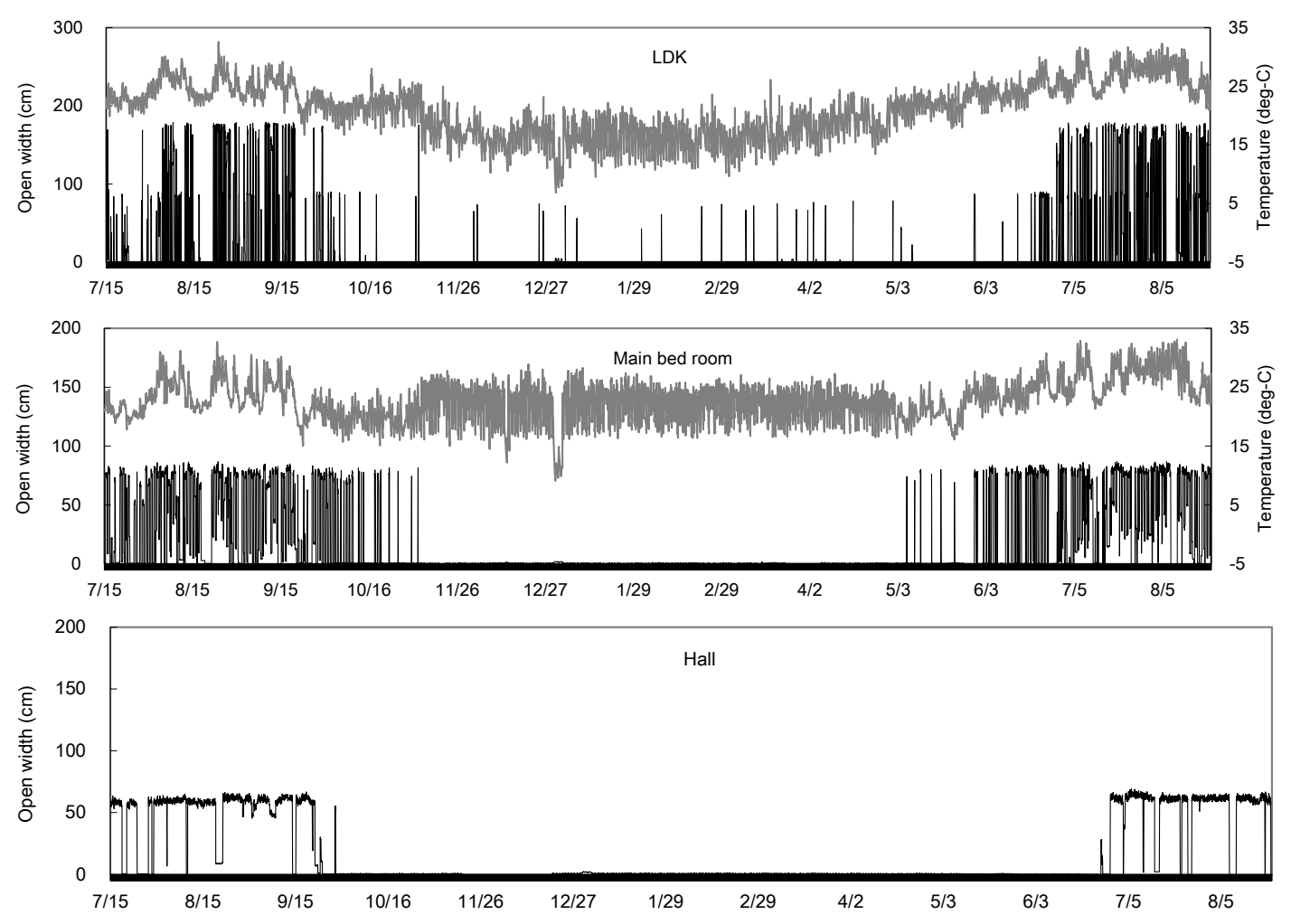

Figure 5. Annual change of the open width and the temperature in a house: Miyagi 1. 
Figure 6 shows the monthly averages of the ambient temperatures and the open widths in four houses in northern area. The open widths in these figures are the averages of the open widths at every measured window in houses. If the windows are fully opened all day, the value becomes almost $80 \mathrm{~cm}$. Therefore the average of open widths is very small even in summer. In most cases, dwellers open windows fully, but for a short time. They close windows at night and when they go out. The answers to the questionnaire on the reasons why the dwellers close windows are outside noise and air pollution, crime prevention, securing privacy and preventing mosquitoes and other insects.

The months when the average open width changes immediately are different from case to case. In the cases of the northern area, Hokkaido, Iwate and Miyagi, the dwellers start to open windows in June when the ambient temperature becomes almost 18 degree-C. In the case of Hokkaido 1, where the ambient temperature is the lowest in nine places, the open width became the highest in July but it was very small. In the case of Iwate 1, the dwellers open windows most widely in August. In the two cases of Miyagi, the open width changes with ambient temperature from June to September. In the case of Miyagi1, the open width decreased in August because they used air conditioner and went out on a trip. In these four cases, the open width becomes very small in October.

Figure 7 shows the cases of southern area. In the case of the southern area: Kanagawa, Kyoto, Nara, Osaka and Ehime, the dwellers start to open windows in May when the ambient temperature becomes almost 18 degree-C. In the case of Kanagawa 1, the dwellers open windows fully from May to July. Kanagawa 1 is located in Hiratsuka City near the seashore, where it is very mild and sunny in spring and hot in summer. The dwellers have a traditional open habit and they open windows intentionally from May to September. However in July and August, they often use air conditioner. In the case of Kyoto, Nara, Osaka, dwellers open windows from May to September. However the open widths were very small. They use air conditioners frequently. In the case of Ehime, the open width was a little larger in July and August. In these southern area as well, the open width becomes very small in October.
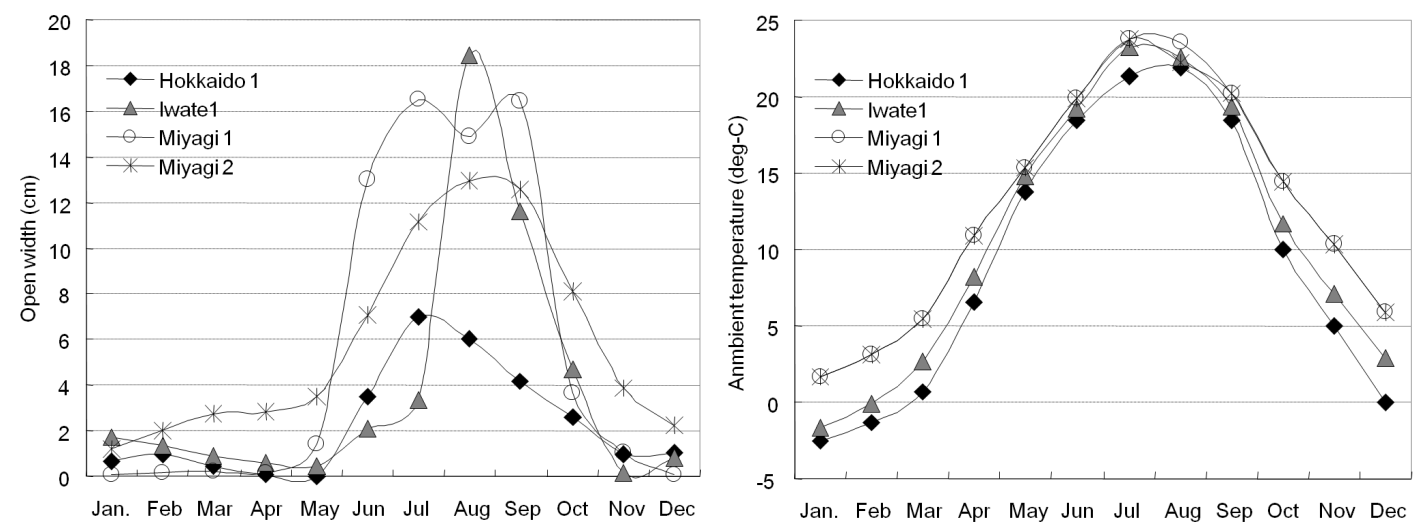

Figure 6. Annual changes of open widths in the investigated houses in northern area.
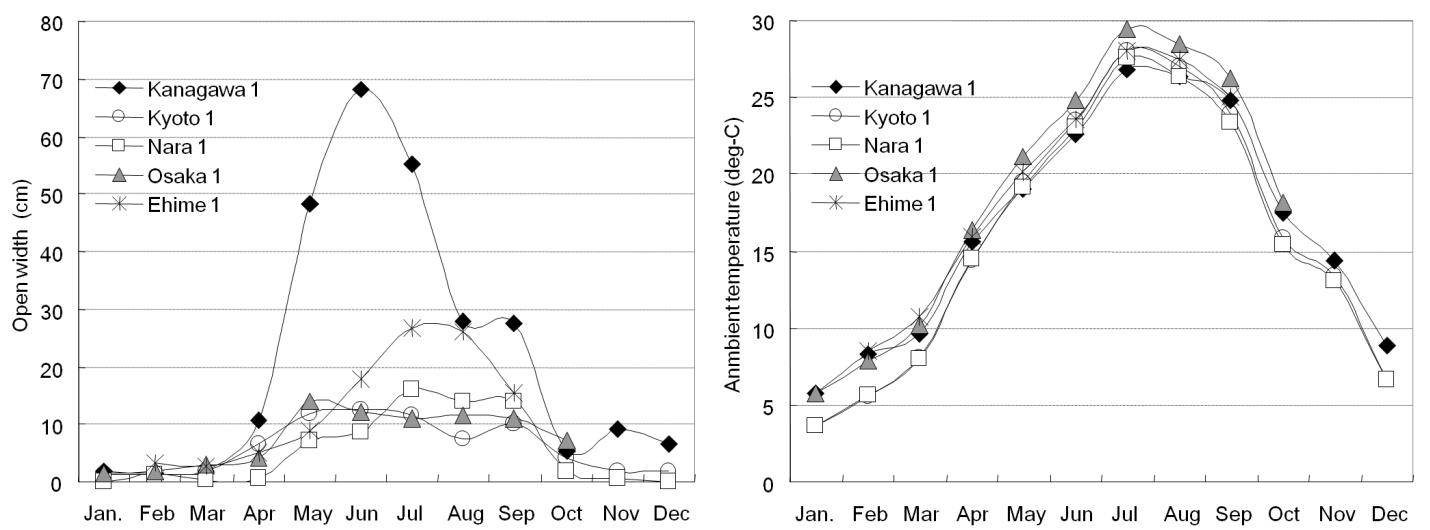

Figure 7. Annual changes of open widths in the investigated houses in southern area. 
Figure 8 shows the relationship between ambient temperature and open width. The open width is smaller than $5 \mathrm{~cm}$ when the ambient temperature is lower than 10 degree-C. In these cold seasons, dwellers open windows temporally for ventilation. The open width becomes larger when the ambient temperature becomes higher than 20 degree-C.

In the cases of southern area, the open width is smaller than $5 \mathrm{~cm}$ when the ambient temperature is lower than 10 degree-C with the exception of Kanagawa 1 . In the case of Kanagawa 1, the open width becomes very large in May and June and decreases after June. But it is still large in July. The decrease of open width is caused by the influence of using air conditioners in July, August and September. In autumn, the ambient temperature becomes lower rapidly and the open width does not become larger again. In the cases of the other houses in southern area, the open width is not so large in July because dwellers use air conditioners more often.

Figure 9 shows the annual cycle of the relation between ambient temperature and open width. In the case of Hokkaido1 in the coldest area of Japan, the open width is very small through the year. The windows are used to control indoor temperature and air quality. The open width is small before May when indoor space is heated. The open width increase in June and becomes the largest in July. The open width decreases after July. The ambient temperature of October is lower than that of May, but the open width of October is larger than that of May. Therefore the annual cycle is basically a left turn.

In the case of Miyagi1, the basic annual cycle is also a left turn. In August, the open width decreases for a while. The decrease is caused by using an air conditioner. In September, the open width becomes larger. The annual cycles of Iwate 1 and Miyagi 2 in northern area are a left turn too.

One of the reasons of the left turn is thought to be the thermal performance of the house; higher insulation level and the heat storage. Another reason is thought to be the delay of dweller's response toward the fall of temperature.

In the case of Nara 1 in the southern area, the annual cycle is basically a left turn but the shape of the cycle is crushed.

In the case of Kyoto 1 near Nara 1, the cycle is a right turn. The open width increases early in spring, April and becomes large in May, June and July. But the open width decreases after July for a while because dwellers use an air conditioner. And the open width becomes large again in September and decreases.

One of the reasons of the right turn is thought to be the dweller's addiction to an air conditioner.

\section{Conclusions}

The aim of this investigation is to save energy for cooling using a passive cooling strategy: wind pass and night purge. The measurement results show that the dwellers do not open windows enough. The open widths basically depend on the indoor and outdoor conditions. However the daily and annual changes of open widths were various. The open widths are influenced by the type of a room, the number of a floor, the living schedule of dwellers and the thermal performances of a house, the equipment for heating or cooling and the living style of dwellers. The cause they habitually keep windows closed is thought to be their living styles and the neighborhood environment of urban areas.
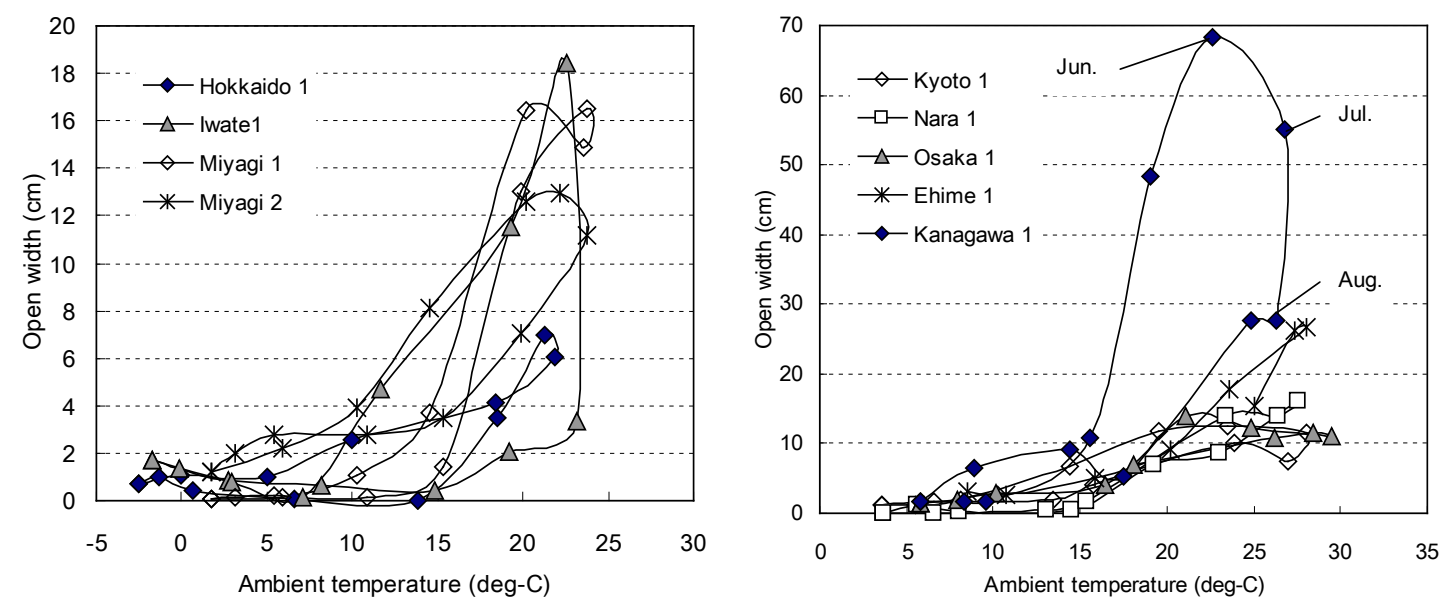

Figure 8. Relationship between ambient temperature and open width. 

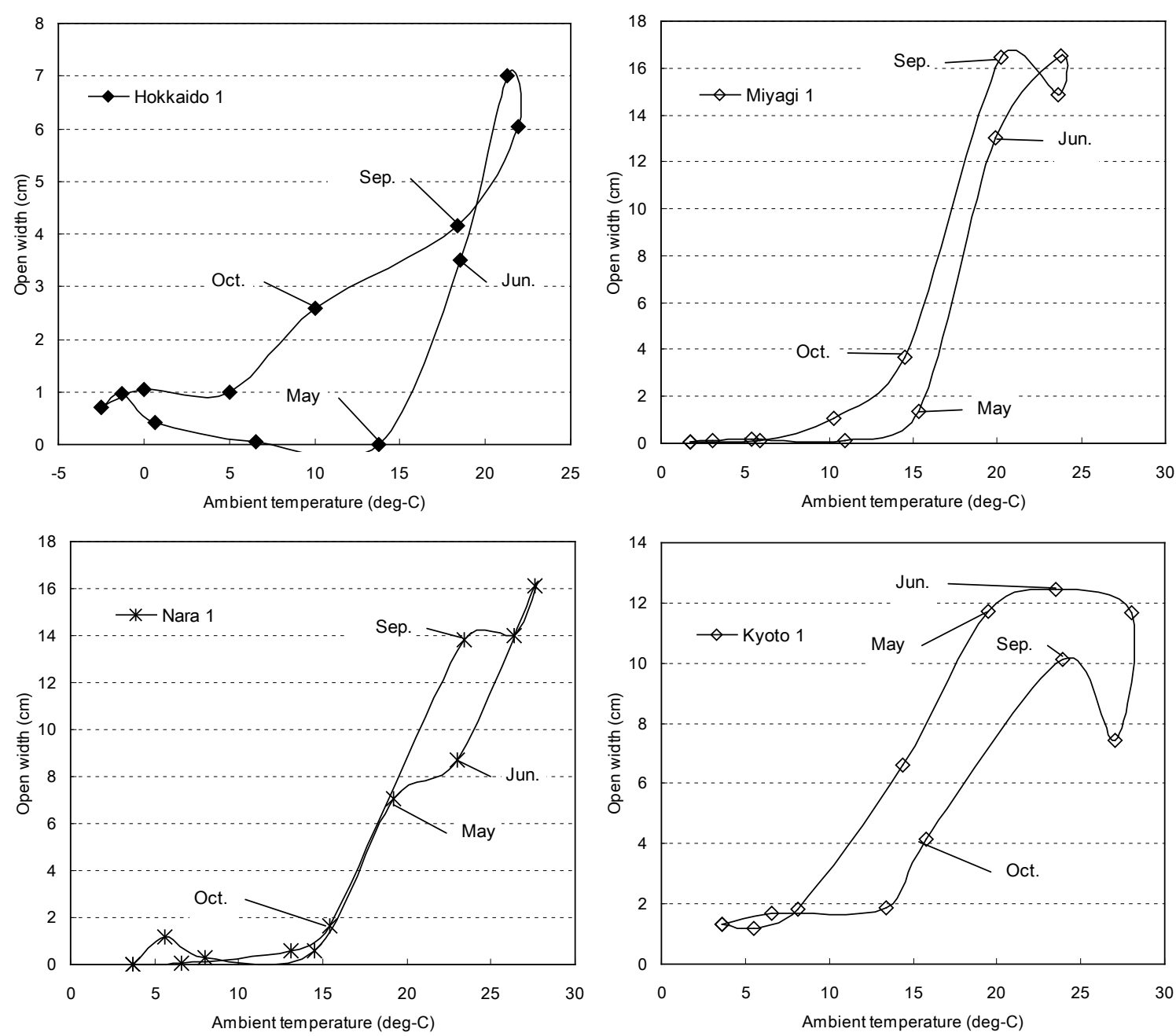

Figure 9. Annual cycle of relation between ambient temperature and open width.

Therefore these factors have to be reconsidered to use windows effectively. For example, the windows which can be left open at night and when dwellers are out are needed. And an outside condition monitor is also needed. To know the effect of these new windows and the equipment, it is necessary to make a flow chart model of operating windows considering the daily schedule of dwellers. The effective temperature and the weather will be considered in operating windows on the flow chart model. The results of the research will be used for the simulation on the indoor climate and energy consumption considering these natural cooling strategies and furthermore, will be used for composing the guidelines to deign openings in sustainable houses.

\section{Acknowledgements}

The study was a part of a national project by National Institute for Land and Infrastructure Management under the Japanese government. The study was carried out with Grant-in-Aid Scientific Research of Japan Society for the Promotion of Science. The investigations were made with the cooperation of Institute for Building Environment and Energy Conservation, the dwellers in the investigated houses and the students of Miyagigakuin Women’s University. The authors express their gratitude to Dr. T. Sawachi and Prof. T. Kurabuchi.

\section{References}

[1] De Dear, R.J, et al. (1998) Developing an Adaptive Model of Thermal Comfort and Preference. ASHRAE Transactions, 104, 27-48. 
[2] Rijal, H.B., Humphreys, M.A. and Nicol, J.F. (2008) How Do the Occupants Control the Temperature in Mixed-Mode Buildings? Predicting the Use of Passive and Active Controls. Proceedings of Conference: Air Conditioning and the Low Carbon Cooling Challenge, Cumberland Lodge, Windsor, UK, Network for Comfort and Energy Use in Buildings, London, 27-29.

[3] Fritsch, R., Kohler, A., Nygad-Ferguson, M. and Scartezzini, J.-L. (1990) A Stochastic Model of User Behavior Regarding Ventilation. Building and Environment, 25, 173-181. http://dx.doi.org/10.1016/0360-1323(90)90030-U

[4] Waren, P.B. and Parkins, L.M. (1984) Window-Opening Behavior in Office Building. AHRAE Transaction, 1B, 10561076.

[5] Rijal, H.B. and Nakaya, T. (2012) Investigation of Window Opening Behavior in Japanese Houses. Proceedings of 7th Windsor Conference: The Changing Context of Comfort in an Unpredictable World Cumberland Lodge, Windsor, UK Network for Comfort and Energy Use in Buildings, London, 12-15.

[6] Hayashi, M., Enai, M. and Hirokawa, Y. (2001) Annual Characteristics of Ventilation and IAQ in Detached Houses Using a Simulation Method with Japanese Daily Schedule Model. Building and Environment, 36, 721-727.

[7] Hayashi, M., Osawa, H., Honma, Y. and Matsui, M. (2007) Prediction of Air Quality Considering the Concealed Air Leaks of Houses. Proceeding of Building Simulation, 870-877. 